This item was submitted to Loughborough's Research Repository by the author.

Items in Figshare are protected by copyright, with all rights reserved, unless otherwise indicated.

\title{
Official recommendations and actual practice in physiotherapy: Managing troubles of physical performance
}

PLEASE CITE THE PUBLISHED VERSION

https://doi.org/10.1515/come.2005.2.2.151

\section{PUBLISHER}

(C) Walter de Gruyter

\section{VERSION}

VoR (Version of Record)

\section{PUBLISHER STATEMENT}

This work is made available according to the conditions of the Creative Commons Attribution-NonCommercialNoDerivatives 4.0 International (CC BY-NC-ND 4.0) licence. Full details of this licence are available at: https://creativecommons.org/licenses/by-nc-nd/4.0/

\section{LICENCE}

CC BY-NC-ND 4.0

\section{REPOSITORY RECORD}

Parry, Ruth. 2019. "Official Recommendations and Actual Practice in Physiotherapy: Managing Troubles of Physical Performance”. figshare. https://hdl.handle.net/2134/32697. 

Managing troubles of physical performance*

\author{
RUTH HELEN PARRY
}

\section{Abstract}

This paper explores relations between official written recommendations for physiotherapists and actual practice. It does so by presenting and discussing findings from a conversation analytic study of 74 physiotherapy treatment sessions video-recorded in four English hospitals. Various practices are described by which therapists address troubles of ongoing or recent physical performance by patients during the phases of sessions occupied with therapists' instructions in treatment activities and patients' physical responses. Divergence between practice and official guidance can be observed, particularly regarding recommendations that therapists always be unambiguous and clear in their communication with patients. Also, there seem to be conflicting demands between maintaining performance of physical treatment activities, and spending time giving patients information and explanation about troubles of performance, and checking their understanding (as is recommended). There are also conflicting demands between individual recommendations. These observations inform a discussion of the wider challenges involved in formulating relevant, appropriate official guidance on communication practice. I argue that the difficulties of auditing actual conduct against official recommendations on interaction should be acknowledged, and that recommendations should be explicitly tentative and broad. Conversation analytic studies can provide resources and understandings to complement and augment such official guidance.

Keywords: conversation analysis; healthcare interactions; physiotherapy; standards of practice; repairs.

Affiliation(s): R. H. Parry (University of Nottingham)

Correspondence to: Ruth Helen Parry

E-mail: ruth.parry@nottingham.ac.uk

\section{Introduction}

In this paper I explore the relations between certain official written recommendations for physiotherapists, and actual practice as observed in a data set of recorded treatment sessions. ${ }^{1}$ These observations lead on to a discussion of the wider challenges involved in formulating official written guidance on clinical communication in such a way that it is relevant and appropriate to everyday practice.

Physiotherapy is a healthcare profession in which physical modalities such as therapeutic exercise and manual therapies are applied to a variety of physical and psychological aspects of health and ill health (CSP 2002). Despite the obvious importance of communication in a therapy in which fundamental objectives are largely achieved through interaction (Dickson and Maxwell 1985), texts and published research in physiotherapy have tended to focus on its technical aspects and to neglect communicative elements (Stachura 1994). In recent years, though, professional bodies, including that in the UK, have begun to pay more attention to communicative elements of practice. This is reflected in recent editions of the 'Core Standards of Physiotherapy Practice' published by the UK's Chartered Society of Physiotherapy (CSP 2000, 2005). These official recommendations include several stipulations about how physiotherapists should communicate. In this paper I explore the relations of some of these stipulations to actual practice by focusing on one part of the interactions-sequences in which therapists address troubles of ongoing or recent physical performance by patients during those phases of sessions that are occupied with instruction and performance of physical treatment activities (as opposed, for example, to history taking or formal examination phases).

In line with concepts described by Peräkylä and Vehviläinen (2003), this conversation analytic study of physiotherapy has both critical and complementary insights to offer with respect to the published recommendations. I show that certain of the official 
recommendations are not feasible in practice and are based upon unsustainable and simplistic assumptions, and that some of the recommendations contradict one another. However, rather than simply condemning discrepancies between recommendations and practice, this study contributes to understanding why therapists and patients behave as they do, and what their practices orient to. Also, I describe ways in which principles laid out in some of the recommendations can be and are implemented in everyday practice. Analysis of this specific setting provides a springboard for discussing some problems in the formulation of official recommendations for good communication practice and how these may be addressed.

\section{Published standards of good practice in physiotherapy}

The standards published by CSP (2005) and other written documents about physiotherapy communication (e.g., Moffett and Richardson 1997; Partridge 1994) have been formulated on the basis of groups of clinicians, and sometimes patients, talking and thinking about practice. That is, they have not been based upon evidence from direct observation. The doctrine or theory underlying current standards is one of 'patient involvement' in the 'active management' of their condition and in decision making (Department of Health UK 1999; Mead 2000). Key to this theory is the assumption that giving patients lots of information and ensuring they understand it will result in their active involvement, and indeed better health outcomes.

Certain of the CSP standards pertain to interactions with patients. Standard 1 states that: 'Respect for the patient as an individual is central to all aspects of the physiotherapeutic relationship and is demonstrated at all times', and a sub-clause stipulates that physiotherapists be 'courteous and considerate' (Criterion 1.2). Standard 12 states that: 'Physiotherapists communicate effectively with patients and/or their carers/relatives' (Standard 12), that they should 'communicate openly and honestly with patients' (Criterion 12.2), and that 'All communication ... is clear, unambiguous and easily understood by the recipient' (Criterion 12.3). Other recommendations concern providing patients with information, giving them opportunities to express their own views and preferences, and checking their understanding. Therapists are told to avoid patronizing patients (Mead 2000) and treating them like children or idiots (Partridge 1994). Although not explicitly stated within the CSP standards, other documents have stated overtly that therapists should communicate in such a way as to encourage patients' motivation (Partridge 1994; Lynch and Grisogono 1991). The professional body regards its standards as attainable and non-compliance as potentially a disciplinary and even criminal matter (CSP 2000; Robinson 2001).

\section{Participants and methods}

The study data consisted of video recordings of treatment sessions in stroke rehabilitation wards. (Strokes are caused by an interruption in blood supply to parts of the brain, causing a variety of impairments, including impairment or loss of movement control of limbs and body.) The 74 treatment sessions constituted just under 50 hours of data. Ethical committee approval and informed consent were obtained prior to data collection. Strategies to minimize the intrusiveness of recording were employed (Jordan and Henderson 1995; Peräkylä 1997). The 21 stroke patient participants ranged from 52 to 86 years old, and included people early and late in their rehabilitation (at first recording they ranged from 3 to 105 days poststroke); ten were male, 11 female. Each patient was recorded up to four times. In all four sites, therapist-patient 'pairings' were fairly stable, with the same therapist usually treating the same patient, and recordings reflected this. The ten therapists had from 3 to 23 years' post-qualification experience; all but one was female.

The analytic process began with watching and making descriptive written logs of all 72 episodes. At this point collections were made on initial themes of interest. The next phase involved selecting four sessions for full transcribing of talk and body movements. The sessions chosen contained most or all elements of treatment that appeared from initial watching to be typical and recurrent. They included patients at various stages of rehabilitation and with different forms of impairment. Gradually, through watching, transcribing, reflecting, studying related literature, and examining data in the company of other researchers, several key themes emerged. More systematic and comprehensive collections were then made.

\section{Analysis}

During performance of physical treatment activities, troubles often arise. These can range from evident difficulty or actual failure in achieving a target made explicit in an instruction-such as to stand up, or to reach and touch an object - to troubles that are not so independently establishable (Schegloff 1979) but are nevertheless oriented to by the therapist or patient. Some of these are actual troubles of performance (such as not achieving smooth movement or symmetrical weight bearing); others are relevant to the level of performance (such as weakness in the arm). Dealing with troubles of, or relating to, patients' performance is a central element of physiotherapy, and 
Table 1. Practices discussed in the paper, and their frequency of occurrence in eight of the recorded physiotherapy sessions

\begin{tabular}{|c|c|c|c|c|c|c|c|c|c|}
\hline \multirow[t]{2}{*}{ Practice } & \multicolumn{9}{|c|}{ Frequencies } \\
\hline & $\begin{array}{l}\mathrm{BT}^{\mathrm{a}} \\
39 \mathrm{~min}\end{array}$ & $\begin{array}{l}\text { MT1 } \\
49 \mathrm{~min}\end{array}$ & $\begin{array}{l}\text { NT1 } \\
41 \mathrm{~min}\end{array}$ & $\begin{array}{l}\text { HT3 } \\
31 \mathrm{~min}\end{array}$ & $\begin{array}{l}\mathrm{DT} 2 \\
28 \mathrm{~min}\end{array}$ & $\begin{array}{l}\text { JT1 } \\
41 \mathrm{~min}\end{array}$ & $\begin{array}{l}\text { NT3 } \\
53 \mathrm{~min}\end{array}$ & $\begin{array}{l}\text { RT2 } \\
41 \mathrm{~min}\end{array}$ & Totals \\
\hline $\begin{array}{l}\text { Follow up instruction to adjust the activity } \\
\text { (the trouble itself is not named directly) }\end{array}$ & 22 & 11 & 8 & 10 & 10 & 14 & 11 & 10 & 96 \\
\hline $\begin{array}{l}\text { Mitigated verbal reference to the trouble with } \\
\text { proposal of remediative action }\end{array}$ & 6 & 8 & 0 & 1 & 0 & 2 & 3 & 4 & 24 \\
\hline $\begin{array}{l}\text { Verbal reference to the trouble produced through } \\
\text { 'perspective display' device, } \\
\text { then recommendation/proposal }\end{array}$ & 1 & 6 & 1 & 0 & 2 & 1 & 1 & 1 & 13 \\
\hline $\begin{array}{l}\text { 'Direct', unmitigated reference to the trouble } \\
\text { within an 'other repair' sequence of three components: } \\
\text { repair initiator, rejection component, repair proper }\end{array}$ & 2 & 3 & 0 & 0 & 2 & 1 & 0 & 1 & 9 \\
\hline
\end{tabular}

relevant sequences were found in every recorded session. For the purposes of this paper, I concentrate on certain of the identified patterns that clearly illustrate how and why practices may conform to, or conflict with, official recommendations. Analysis here is confined to episodes that arise during those phases of treatment sessions predominated by the therapist's production of instructions to perform treatment activities (movements), and patient's physical responses. I have not included analyses of episodes in which the patient rather than the therapist initiates verbal reference to a trouble in their performance, although such episodes do occur (Parry 2004: 991-993).

Table 1 briefly lists the practices discussed in this paper. It also reports a rough count of the frequency of occurrence of these practices in eight of the recordings (just over $10 \%$ of the data). The problems of applying quantification to interactional data are considerable (Schegloff 1993), and thus the frequencies should be taken as indicative rather than absolute. The total volume of data precluded frequency counting for all sessions, so counts were performed on the four fully transcribed sessions and a further four chosen via random number tables. The most frequent of the practices examined in this paper was the production of what I have termed 'follow-up instructions'. Apart from this practice, all the others entail some form of verbal reference to, i.e., naming of, the trouble. This is most commonly done in a 'delicate', sensitive manner, with sequences involving more direct verbal reference to the trouble being the least frequent.

The extracts presented in this paper were chosen because they illustrate certain patterns of conduct particularly clearly. Transcript conventions for verbal conduct are found in the Introduction to this special issue. Some of the transcripts in this paper include simplified transcription of body movements. Transcripts are arranged with multiple horizontal lines representing talk and nonverbal activities. Body movements are shown in italicized text; therapists' movements are written above verbal activity lines, patients' below. Where a movement activity starts part way through a verbal turn, this is indicated by the positioning of the italicized text. ' $\mathrm{T}$ ' indicates the therapist's talk or movement, 'P' the patient's. All names in transcripts are pseudonyms.

\subsection{Sequences where no troubles of performance are oriented to}

The first extract provides some context by showing an episode in which no troubles are verbally identified, implied, or in any other way oriented to by participants. Such episodes entail repeated sequences constructed of brief instructions (I) to perform a next element or to continue or repeat the activity, and closely linked physical responses $(\mathrm{R})$ by the patient (e.g., lines 1-6). These I-R-I-R sequences can function to indicate trouble-free progress of activities, and have been identified in other situations of teaching embodied activities: Curley (1998), who examined teaching of a Japanese tea ceremony, observed that by giving an instruction for the next part of an activity, the teacher can accept what has been done and demonstrate its correctness. Also, there are often 'positive' evaluations (such as 'yeah' and 'that's it') by the therapist prior to the next instruction (e.g., line 13). Similar Instruction-Response-Evaluation plus next instruction (I-R-E) sequences are recurrent in classroom interactions (e.g., Mehan 1985; McHoul 1985).

(1) (Site 1, Therapist 1, Patient B)

1 T:.${ }^{\circ} \mathrm{OK}$ reaching forwards forwards $\uparrow$ there

$2 \mathrm{P}$ : starts to lean forward

$3 \quad(4.0)$

4 T: leans to touch stool

5 T: ${ }^{\circ}$ and back up again ${ }^{\circ}$

6 P: comes back up 
$7 \quad(2.5)$

8 P: glances to T's face when upright, and lowers hands

9 T: ${ }^{\circ}$ al $\uparrow$ right and again ${ }^{\circ}$

10 P: $\wedge$

raises hands

\section{leans forwards again}

$11 \quad(5.0)$

12 P: leans to touch stool

13 T: $\downarrow$ that's $\uparrow$ it and back up $>$ an jus do

14 P: $\wedge$

15 T: it one more ...

starts to move back up

\subsection{Orienting to trouble without naming it: Follow-up 'adjusting' instructions ${ }^{2}$}

'Trouble free' I-R-I-R or I-R + (positive)E sequences like that in Extract (1) are found in most of the recorded sessions. However a different pattern, shown in Extract (2), is more frequent. In this pattern, the therapist's turn after, or co-incident with, a patient's physical response is formatted as an instruction that does not project simple continuation or repeat, nor a move on to a next, new action. Instead the therapist's turn in some way calls for some adjustment or amendment of the prior or ongoing action, or re-emphasizes a part of the first turn instruction.

(2) (Site 3, Therapist 5, Patient N)

$1 \mathrm{~T}$ : ${ }^{\circ} \mathrm{OK}^{\circ}$ (.).hh (.) $\uparrow$ really = really gently

2 T: what I want us to try and $\uparrow$ do

3 (0.5)

$4 \mathrm{~T}$ : .hh is $\uparrow$ just move your weight from $\uparrow$ one

5 P: body sways from one side to the other

$6 \quad$ T: $\operatorname{leg}($.$) to the other$

7 P: $\mathrm{mm}$ oh y[es]

8 T: $\quad[\uparrow$ re]ally gently so not

9 P: still swaying

10 T: $\uparrow$ your shoulders

11 (1)

12 P: somewhat jerky movement of hips, shoulders move less

\section{$13 \mathrm{~T}:{ }^{\circ} \mathrm{O} \uparrow \mathrm{K}^{\circ}$}

Subsequent to an initial instruction from the therapist (lines 1-6), and after physical response(s) by the patient have commenced, the therapist produces a further, third position, instruction ' $\uparrow$ really gently so not $\uparrow$ your shoulders'. This emphasizes an element contained in the previous instruction (really gently), and projects an adjustment (not moving the shoulders). It could thereby verbally imply troubles, although there is an ambiguity here, which I discuss further below. In other episodes, rather than being implied in the format of the third position instruction, the trouble is evident through other sequential aspects-Extract (3) is an example.

(3) (Site 3, Therapist 5, Patient N)

1 T: touch my hand down here

2 P: reaches to T's hand

$3 \quad(1.5)$

4 P: reaches, but doesn't touch; glances to $T$ as she comes to a stop

$5 \mathrm{~T}:$ raises her right hand to P's shoulder $\checkmark$

6 T: go on have a reach forward for me 7 P: $\wedge$ reaching more and leaning forward $\wedge$ touches T's hand

9 T: $\uparrow$ that's lovely (0.2) $\mathrm{O} \uparrow \mathrm{K}($.$) now down here$

In this extract, there is evident, visible failure to achieve a target that was established within the initial instruction; the patient's glance (line 4) may also contribute to evidencing troubles. The third position instruction in this extract (line 6) is formulated as encouraging, and asks for an adjustment, leaning forward. Without other aspects of the sequence that evidence troubles, this could be taken as an instruction for next action rather than an adjustment and correction of prior performance. Generally, the follow-up instruction strategy can be seen in both extracts above to be effective, in that there is a rapid patient response that, at least partially, adjusts or amends prior performance (Extract [2], line 12; Extract [3], line 7). Also, uninterrupted performance of movement activities is maintained in both these extracts.

In these physiotherapy data then, follow-up 'adjusting' instruction sequences sometimes involve a trouble of performance that is evident through failure to achieve a target established by a first position instruction (as in Extract [3]). However, trouble can be evidenced in several other ways, for instance through patients themselves characterizing it verbally, or physically_-such as by hesitating or making effortful-sounding vocalization. Another way by which troubles are evidenced is through therapists' body movements: ${ }^{3}$ therapists sometimes make rapid physical adjustments during patients' second position responses-reaching out quickly to provide physical assistance or guidance, or to 'catch' or halt movement. Sometimes, third position instructions include some form of verbal but indirect indication of troubles. Occasionally this is through production of a 
repair initiator (such as 'ooh'), but more often through other formulations (as in Extract [2]). Common to all follow-up instructions, though, is their non-explicitness about the trouble or shortcoming they are addressed to. Indeed where there is no repair initiator, there is ambiguity as to whether a shortcoming or trouble is indeed being addressed, because there is not always a distinct boundary between follow-up adjusting instructions and instructions in a next, different activity.

The non-explicit characteristic of follow-up instructions can make analysis challenging. However, in terms of the interactional context of physiotherapy, ambiguity as to whether or not there is some form of trouble in the patient's performance is highly functional. An understanding of why this is so can be developed by examining parallels between this practice and one that has been identified within everyday talk-in-interaction- 'embedded correction' (Jefferson 1987). Jefferson described a distinction between 'embedded' and 'exposed' corrections of troubles in speaking, hearing, and understanding talk. In embedded corrections, 'next speaker produces an utterance which is continuous with ongoing talk, which happens to have an alternative item [an alternate from the same syntactic class, or an alternative pronunciation], then prior speaker produces continuous talk which happens to repeat the alternative' (Jefferson 1987: 98). Exposed corrections (in brief) involve explicit correction of one person's talk by an interlocutor, and a shift to utterances that are 'occupied by the doing of correcting' (Jefferson 1987: 88). An important facet of exposed correction is that it allows for inclusion of such activities as explanations, apologies, and instructions. This contrasts with embedded corrections, which do not provide sequential opportunities for such things.

Clearly, in comparison with Jefferson's data set, the physiotherapy data involve a very different context and a specialized turn-taking organization: one party is directing and describing movements through talk, the other is physically performing movements. 'Other corrections' in physiotherapy involve therapists orienting to troubles of physical performance rather than troubles of hearing, speaking, and understanding talk. Nevertheless, there seems to be a parallel between embedded corrections and the practice of managing troubles through follow-up 'adjusting' instructions: because the therapist's turn following a patient response is formulated purely or partially as an instruction, this allows the overall I-R-I-R pattern to be maintained. Thus, like Jefferson's embedded corrections, this pattern can mean the correction does not become the 'interactional business', but happens 'as a by-the-way occurrence' (Jefferson 1987: 95) within the ongoing activity.

Now, in terms of the institutional tasks of physiotherapy, dealing with troubles of physical performance through follow-up adjusting instructions has limitations because they do not allow for discussion and explanation of the nature of the problem, nor of how it can be dealt with. In this sense, the practice I have described seems to conflict with aspects of official recommendations, including stipulations about being direct and unambiguous, and exhortations to check patients' understandings and views. Since the trouble is not 'on the surface', neither it nor its consequences are available as a topic for dialogue between therapist and patient. Furthermore, neither analyst nor therapist has any indication of the patient's perspective and understanding of it. On the other hand, it could be argued that this practice constitutes 'effective communication' (as per CSP Standard 12) in terms of getting the organizational tasks of physiotherapy done-it tends to result in rapid correction of the error, and involves continuation rather than interruption of physical treatment activities.

Jefferson (1987) also pointed out that embedded corrections can function to keep issues of incompetence off the interactional surface. Similarly, followup adjusting instructions allow avoidance of any direct reference to incompetence, and thereby maintain some ambiguity as to whether any trouble of competence is indeed being dealt with. Thus, this practice is consistent with a regular orientation of therapists and patients to avoiding or limiting verbal exposure of physical incompetence, which I discuss further below. For now, and to gloss, we can say that by avoiding direct reference to the patient's shortcoming or failure, this practice could be described as constituting courteous and considerate communication with patients (Standard 1, Criterion 2).

In the next practices I describe, there is verbal reference to troubles of, or relating to, performance. Before describing these, it is worth pausing to briefly examine the interactional troubles that can be associated with verbally referring to a co-interactant's physical incompetence. When physical incompetence becomes an interactional issue, people recurrently appear to treat it as giving rise to negative implications. These include the possible interpretation that incompetence reflects a lack of effort on the part of the patient, and/or a failure to co-operate with therapeutic assistance and direction (Parsons 1951; Parry 2004), and the possibility that it indicates the patient is incompetent at a wider, 'essential' or personal level (Goffman 1969, 1981). In addition, when incompetence reaches the interactional surface during physiotherapy, it has the potential to prompt expression of patient distress and 'demotivation', and to undermine the sense that therapy is functioning successfully and that participation in it is worthwhile (Parry 2004). Thus, it seems likely that in interactional terms there will be tensions between, on the one hand, the physiotherapeutic task of identifying, providing information about, and correcting patients' troubles of, or relating to, performance of movements and, on the 
other hand, the need to attend to issues of courtesy, consideration, respect, and motivation.

\subsection{Naming the trouble}

Three practices are examined in which the trouble is named. In the first two, this is done in a manner that indicates delicacy and sensitivity with respect to exposing troubles; the final one is more direct and appears more similar to sequences of 'other repair' that are seen in everyday talk.

\subsection{Minimizing and mitigating verbal reference to the trouble}

The first practice involves referring to the problem in ways that minimize and otherwise mitigate it. This can be done in several ways, including use of particular descriptors, 'depersonalizing' the problem, and accompanying negative evaluations with evaluations of more positive aspects of performance. These features can make for somewhat indirect talk about the trouble itself. Extract (4) gives an example. The patient is lying on the treatment bed and has been performing a series of arm exercises, with the therapist providing physical resistance-a form of strengthening exercise. The extract begins in the midst of the performance of one of these movements. (Note that English is not this patient's first language. His talk presented some difficulties for the analyst in transcribing and the therapist can be seen during the sessions to have problems understanding some of his talk.)

\section{Extract (4) (Site 3, Therapist 6, Patient O)}

$1 \mathrm{~T}$ : .hh $\uparrow$ an a $\downarrow$ gain so fingers $\uparrow \underline{\text { back. }}$. wrist

$2 \mathrm{~T}: \uparrow$ back and < straighten $>$ yer el $\downarrow$ bow $=>$ think

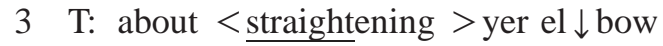

$4 \quad(0.5)$

5 T: .hh and then $\uparrow$ squeeze and come $\downarrow$ down

$6 \quad(0.2)$

7 P: arm moves back down to the bed

8 T: gestures bending of the elbow $\checkmark$

9 T: OK.hh yer $<\uparrow$ really strong now (0.2).hh

10 T: $\uparrow$ he: $\downarrow$ re (.)with the $\uparrow$ ben[d::.hh]

11 P: [yeah]

12 T: that's $\uparrow$ really really strong..hh it's more

13 T: at the $\uparrow$ back

$14 \mathrm{P}$ : =yes

15 T: that's it still a- a $\uparrow$ liddle bit weak

$16 \mathrm{~T}$ : > although it's a lot $=$ lot $<\underline{\text { stronger (.) }}$

17 T: $[\mathrm{O} \uparrow \mathrm{K}]$

18 P: $[(\quad)]$

19 P: (

$20 \mathrm{~T}:(($ laughing $)) \mathrm{hm} \mathrm{hm} \mathrm{hm} \mathrm{hm}{ }^{\circ} \mathrm{h} \uparrow \mathrm{SO}$

21 (0.2)
22 T: .hh I want you to re $\uparrow$ lax the $\uparrow$ top

23 T: half of yer arm

24 P: $\mathrm{mm}$

25 T: looks down to patient's forearm

26 T: $\mathrm{O} \uparrow \mathrm{K}$. and we're $\uparrow$ just

27 T: gunna $\downarrow$ go:.hh

28 P:

$\wedge$

$29 \quad(0.5)$

$30 \mathrm{~T}$ on $\uparrow$ that movement

The therapist's talk from line 9 onwards orients to a trouble closely related to his recent performance of an arm strengthening exercise. Her evaluation of muscle weakness in part of the arm is mitigated or "cushioned' in several ways. These include its lexical form: 'a $\uparrow$ liddle bit' and the way it is accompanied by an indication that even though there is a problem, there is nevertheless progress: 'although it's a lot lot stronger'. A further mitigating element concerns the way that the initial positive assessment is personalized 'yer really strong now' whereas the negative assessment that follows is not: 'that's it still a- a $\uparrow$ liddle bit weak'. This strategy of depersonalizing the referent of a problematic assessment has been previously noted in other interactions that involve delicate physical problems (Weijts et al. 1993). Other minimizing/mitigating formulations seen in the physiotherapy data involve things like: 'the only thing we need to work on now is ...', and also the use of evidential formulations (Chafe and Nichols 1986; Heritage and Stivers 1999) such as: 'looked like you might have needed to bring your weight a little bit further forwards'. These patterns of therapist conduct have the function of insulating a specific area of incompetence from the rest of the behavior and offsetting any implication of 'personal' incompetence (cf. Goffman 1969, 1981). Thus, although this therapist exposes a problem of the patient's competence, she does so in a way that limits any associated implication of personal insufficiency on the part of the patient.

Another notable feature of this extract is the close sequential and temporal link between the therapist's verbal identification of a trouble, and the proposal and conduct of a remedial activity. This feature is seen across many similar sequences in the data, including the next extract. Also, Maynard (1992) found a similar pattern in doctors' conduct. Potentially, incompetence in performing physical activities could be 'read' as indicating that therapy is failing, and could thus undermine the rationale for participating in it. This interactional strategy of closely linking remedies to any exposure of physical difficulty, as well as linking with notions of progress, constructs incompetence as something which indicates the need for further therapy and which can be improved thereby, rather than something which signals that therapy is not working. 


\subsection{Therapist seeks patient's perspective on the trouble}

Another strategy involves verbally but sensitively referring to the trouble: the therapist solicits the patient's perspective relating to a trouble prior to producing evaluations and proposals that orient to dealing with it. This pattern resembles the perspective display sequence or device described by Maynard (1989). He noted that in everyday talk, the sequence forms 'a strategy for giving an opinion by first soliciting another party's opinion and then producing one's own report in a way that takes the other's into account' (Maynard 1989: 91). Maynard (1991a, b, 1992) demonstrated that the sequence is used and functions in particular ways in a pediatric diagnostic clinic setting. Silverman (1997) has observed its use in a counseling setting. He found that during certain advice-giving sequences 'the professional only delivers advice after a "problem" has been identified in an answer to the professional's question' (Silverman 1997: 160). Extract (5) gives an example from the physiotherapy data.

\section{(5) (Site 3, Therapist 4, Patient M)}

1 T: stand up ag $\uparrow$ ain

$2 \mathrm{P}:$

he commences move to standing

\author{
$3 \quad(2)$ \\ 4 T: ((louder)) where d'you think your \\ 5 T: weight is George \\ $6 \quad$ (.) \\ 7 P: err a lot of it on me right right side. \\ $8 \mathrm{~T}:={ }^{\circ}$ yeah $^{\circ} . \mathrm{hh}$ \\ $9 \quad(0.5)$ \\ $10 \mathrm{~T}:>$ (think) praps if we put a \\ 11 T: $\uparrow$ mirror in front of you <you'd \\ $12 \mathrm{~T}$ : see that you sort of \\ 13 T: [(.) leaning over that way a] little bit \\ 14 P: [yeah tippin over a bit ] \\ 15 P: yeah
}

Prior to this extract, a sequence of instructions and responses has been in progress, with the patient repeatedly standing up and sitting down again. At lines 4-5, the therapist asks a question that in this context implies some possible trouble-it seems reasonable to assume that both will be aware that the idea of standing up is to have weight upon both sides or feet. The patient's response thus indicates awareness of this trouble. The therapist produces immediate brief agreement (line 8), then a turn that incorporates a proposal to help remedy the trouble, as well as a mitigated naming of it: 'you sort of (.) leaning over that way a little bit'. By soliciting the patient's view relating to some trouble, the therapist can then introduce talk about it—such as evaluations and proposals for remedies - in a 'hospitable' environment (Maynard 1992). Additionally, in utilizing this pattern, the therapist both seeks and indicates attention to the patient's perspective and understanding. It also functions as a way of calling a patient's attention to his performance without immediately and directly producing a negative assessment, and in this way cushions it. The practice seems consistent with the official physiotherapy recommendations in that it provides patients with opportunities to express their own understandings and views, and in this way could be said to enhance patients' involvement in the interaction.

In the two practices illustrated in Extracts (4) and (5), the trouble becomes the topic of the interaction and there is sequential opportunity for talk about it. In their sensitive dealings with shortcomings and failures, both practices seem to attend to recommendations about courtesy and respectfulness, and to other recommendations that therapists communicate in such a way as to encourage patients' motivation. On the other hand, both practices could be construed as involving rather indirect communication. It is also noticeable that, in practical terms, these ways of managing failures of patients' movements involve interruption of ongoing physical treatment activities and have the potential to be quite time consuming.

\section{6. 'Direct' repair with three components: Initiation, rejection component, and repair proper}

Compared with the other practices examined, this final practice entails more direct verbal reference to troubles of performance and more closely resembles the pattern of third-position other repair of troubles of speaking, hearing, and understanding that has been identified in studies of everyday talk in interaction (Schegloff 1979, 1992; Jefferson 1987). In brief, Schegloff argues that these 'have a highly recurrent form and are constructed from four main types of components' (Schegloff 1992: 1304), which almost always occur in the same order. One of these components ('agreement/acceptance') relates to a rather specific situation, which I have not observed in my data; the other three components are: a repair intiator, commonly taking the form 'no'; a rejection component, with which 'the speaker overtly rejects the understanding that prior turn reveals its speaker to have accorded the trouble-source turn' (Schegloff 1992: 1306); and the repair proper, in which the 'speaker carries out some operation or operations on a prior turn, so as to address the problematic understanding of it revealed by an interlocutor's response' (Schegloff 1992: 1308).

Full-blown comparative analysis would require lengthy consideration of both the complex relationship and key differences between practices of 'other repair' in everyday talk, and the related but different practices found in this setting. It is beyond the scope of this paper to discuss these. It is worth noting here, 
though, that the organization of this phase of physiotherapy interactions is very different to the organization of everyday talk in interaction. Also, the troubles considered here do not have their roots in troubles of hearing, speaking, and understanding of the prior instruction turn (or do so only rarely), but rather they result from lack of competence to perform or complete a response to it, and possibly in a limitation of effort and cooperative participation. This issue, together with the interactional troubles of exposing these forms of troubles, underlies at least some of the key differences between 'other repair' in everyday talk, and practices seen in these data.

Returning to the three-part initiation-rejectionrepair proper sequence, as noted earlier, it occurs infrequently in the physiotherapy data, despite its directness and relative lack of ambiguity. Preliminary observations about those occasions on which 'threecomponent repairs' are seen suggest they occur in particular situations. These include circumstances in which the same trouble has been repeated several times and less direct approaches to dealing with it have been made to no avail, and in other situations in which the patient accompanies their physical $\mathrm{r}$ esponse with talk about what they are doing-the subsequent repair can thus be made upon the patient's talk (this was the case in Session DT2 in Table 1). The pattern appears more frequent in treatment sessions that involve patients for whom direct exposure of incompetence might be anticipated to be less interactionally problematic (for instance, less surprising or distressing), such as patients who are quite experienced in therapy and with whom there has already been much overt talk about physical incompetence (Sessions BT2 and MT1 in Table 1). Extract (6) gives an example of three-component repair.

\section{(6) (Site 3, Therapist 4, Patient M)}

\begin{tabular}{|c|c|}
\hline $\mathrm{T}:$ & just trying to $<$ lift your leg (.) \\
\hline $\mathrm{T}:$ & forwards and down \\
\hline & $(0.5)$ \\
\hline $\mathrm{T}:$ & and then back onto my knee \\
\hline $\mathrm{T}$ : & $\mathrm{OK}{ }^{\circ} \mathrm{h}$ \\
\hline $\mathrm{T}:$ & $=$ NOW (.) can already see that your \\
\hline $\mathrm{T}:$ & hip's kind of (.) turned out as \\
\hline $\mathrm{T}$ : & you're trying to sor' of lift it like \\
\hline $\mathrm{T}:$ & th[at alright] \\
\hline P: & [mmh huh] \\
\hline $\mathrm{T}:$ & $\begin{array}{l}\text { so I want to try and keep yer knee } \\
(0.5)\end{array}$ \\
\hline & over here \\
\hline
\end{tabular}

It is noticeable that even where the pattern does occur in the physiotherapy data, the components are not as forthrightly 'rejecting' as those found in examples given by Schegloff (1992) and Jefferson (1987). The repair initiator (line 6) is 'NOW', rather than 'no'; this is consistent with findings that in teaching interactions, teachers tend 'to prefer tentative or mod- ulated initiations ... over definite or direct ones' such as 'no' (McHoul 1985: 62). Also, the rejection component is not formulated in terms of 'not X' or 'don't do X', but the softer 'can you see that' and the mitigated 'your hip's kind of turned out' (lines 6-7).

\section{Discussion}

Rather than being 'open, honest, direct and unambiguous' as stipulated by the written recommendations, the therapists in these data frequently employed practices that were indirect, not fully 'open' about the trouble, and as such could be described as ambiguous. This is consistent with findings in other settings. For instance, in classrooms, when pupils give wrong answers, rather than directly identifying and correcting deficiencies of these answers, teachers respecify questions and/or give prompts and clues (McHoul 1985). Speech and language therapists frequently avoid direct reference to and direct correction of patients' non-competence of language (Lindsay and Wilkinson 1999). I have shown that there can be good reasons for practices involving ambiguity and indirectness in physiotherapy. Finding 'good reasons' is also consistent with previous analyses-Silverman (1997: Chapter 8) found that in HIV counseling, counselors sometimes employ an ambiguous communication format in order to manage the potential interactional difficulties entailed in raising certain delicate topics with clients. More broadly, findings that clinicians expend considerable interactional efforts in respecting and 'protecting' patients' feelings are consistent with previous ethnographic findings (Strong 2001).

Discrepancies between official recommendations and actual practice have been observed in this study and others (Beach 1995; Ruusovuori this issue). Such analyses provide a stimulus to understanding why it is that some official recommendations, which attempt to stipulate good communication practice and against which practice is supposed to be measured, seem to be inappropriate or unusable in practice. Recommendations that are problematic in this way are predicated upon a lack of knowledge and a range of misunderstandings about communication and language use. A discussion of these will lead to some proposals for the formulation of written recommendations about communication practice.

Analysis of the data in this study showed that some official recommendations fail to take into account the requirements of the practical work and social orientations involved in everyday practice. For instance, the guidelines recommending that therapists always be unambiguous, clear, and honest in their communication with patients seem inappropriate to aspects of practice and conflict with social orientations to dealing with others' physical failures or shortcomings. However, there is a more fundamental problem for 
recommendations that physiotherapists' communication be open, honest, clear, and unambiguous. A sophisticated ethnomethodogical understanding of how language and communication function reveals that it is impossible to be fully, or 'finitely', unambiguous and clear in communication (see Heritage 1984: 134-159). It is important to recognize that the establishment of meaning through talk is not 'the product of shared semantic representations-a sort of mental dictionary that all speakers can look up' (Potter 1996: 44). It would actually be impossible for language to function in this way, because every situation is unique, and so we would require an infinite number of terms within this dictionary. Rather than meanings being based on some 'literal', direct correspondence between something in the world and a word or phrase, meanings are generated and established through applying a range of interpretive processes to a reasonably small vocabulary. That is, speakers and hearers tacitly rely on and employ a range of methods that involve 'continual invocation of common sense knowledge and of context as resources with which to make definite sense of indefinite ... terms' (Heritage 1984: 144). All words and utterances are thus indexical-reliant for their meaning on their context of use. Through applying interpretive processes, people come to understanding and clarity of meaning that is sufficient 'for all practical purposes'. We can, however, never know whether understanding is 'full', or completely clear and unambiguous-this would only be possible if humans were telepathic.

To give a concrete illustration of some of these issues, see Extract (1), line 9. The therapist's 'alright and again' is produced and responded to as a meaningful instruction to the patient to lean forward and reach her hands towards the stool, because therapist and patient employ common sense and contextual knowledge to this highly indexical utterance. Notice that both therapist and patient are involved in achieving the meaning of the utterance, and that meaning is produced and established over the course of a sequence of utterances and actions.

This characteristic of how meaning is achieved presents further problems for the recommendation that communication be clear and unambiguous: the recommendation exhorts and applies to just one partythe therapist-but the interactional property it concerns requires collaborative activities that involve therapist and patient. This issue provides some insight into why there seems to be less discrepancy (in this study at least) between practice and official recommendations that therapists be courteous and considerate in their communication. These properties seem to relate more directly to the way that one party attends to another, rather than to collaborative processes, and as such may be more achievable by the therapist in practice. Nevertheless, when we come to consider using official guidance as standards against which to measure actual conduct, further problems arise with respect to all of these recommendations, including those about respectfulness, consideration, and courtesy.

As noted, the meaning and character of communication are locally accomplished. To further explain this in situ constitution of meaning and to elucidate its implications for recommendations about communication practice, let us return to the CSP standards (2005), specifically to some of the standards that do not concern face-to-face interaction. For instance, it is stated that 'Patient records are started at the time of the initial contact' (Standard 14, Criterion 1) and are 'Signed after each entry' (Standard 14, Criterion 4.7). It would be relatively easy to analyze, through audit or disciplinary committee, whether such a practice had occurred. The evidence would consist of the records themselves-material objects that can be examined (fairly) independently of their original context. However, no such 'external' material objects exist to evidence the character of clinical communication. Rather, the specific individual context and the local moment-to-moment actions and responses of therapists and patients are central to the constitution of its meaning and character. Hence, although some sort of determination as to whether treatment records were fraudulent would of course be needed, analysis and examination of this aspect of practice seems far more straightforward than analyzing and measuring whether a therapist's communication with a patient was respectful, courteous, clear, or unambiguous.

Any strategy for making this sort of judgement about communication is fraught with problems. For instance, we might gather people's post hoc reports of their perceptions of the communication. However, these have a very indirect and complex relation to what actually occurred, and may depend on a huge variety of social and personal factors and issues arising outside the interaction itself (Murphy and Dingwall 2003), and there would also be good reasons for expecting widely differing views from different participants on the interaction (Murphy and Dingwall 2003; Stimpson and Webb 1975). Alternatively, we could try to judge the character of communication through the rigorous scrutiny afforded by methods such as conversation analysis. However, analysis would only be possible where episodes had been recorded. Furthermore, even where recordings were available, this analysis would not itself provide judgements as to what constitutes, for example, 'effective', or 'considerate', or 'honest' communication (see Maynard 1991b). For this, further subjective, ad hoc interpretations would be necessary. This level of interpretation is very different to that needed when judging whether a patient's records are signed after each entry. Using written stipulations for auditing or judging practice is therefore a very different matter for technical tasks than for interactional qualities. 
One final issue relevant to the formulation of recommendations relates to the way in which any one communication practice has a variety of interactional consequences. For instance, this study showed how the 'follow-up instruction' pattern of dealing with shortcomings in patients' performance allows for rapid correction of errors and the continuation of treatment activities, but means limited patient involvement in terms of providing information, checking understandings, and seeking their views. This complexity of effects, benefits, and disadvantages of communication practices makes for difficulties in recommending or prohibiting specific practices. Beach's (1995) study gives a nice illustration of the potential problems of recommending or prohibiting specific practices: he takes as a starting point a recommendation by a medical school that doctors avoid using the term 'Okay' in interviews with patients, he then empirically examines the complex functioning and utility of 'Okay' in real life medical interactions, and concludes that prohibiting the use of 'Okay' could result in considerable interactional trouble.

Elucidating these various issues provides a basis for making some reasoned proposals about how official guidance could be made more appropriate and relevant to practice. Firstly, it would seem useful to acknowledge within official guidance both the complexity of communication and meaning, and the problem of auditing actual conduct against standards pertaining to interactional practice. The discussions above suggest that the more directive and specific a recommendation, the greater is the need to base it upon a thorough understanding of the interactional tasks and strategies involved, developed through direct observation. It may indeed be better to produce recommendations that are explicitly tentative and refer to broad principles rather than specific directives. These would leave sufficient 'space' for therapists to improvise and establish effective communication in the light of local circumstances. ${ }^{4}$ To do so, therapists need to be enabled to understand as much as possible about clinical communication and the orientations that shape it. They also need to be aware of different practices and their functions and consequences, allowing them to weigh up advantages and disadvantages. Conversation analytic studies can help meet these needs by providing detailed analysis and authentic examples of the practices and challenges that arise during interactions, elucidating their functions and effects, and the orientations that underlie them. Thus, this sort of research and the recordings that form its data have great potential as resources for facilitating reflection on and teaching of interactional skills, and thus supplementing official recommendations.

\section{Notes}

Thanks are extended to the physiotherapist and patient participants, to Alison Pilnick and Robert Dingwall as supervisors of the Ph.D. thesis that this paper draws upon, and to the skilled, anonymous reviewers of a previous version of this paper.

1. Physiotherapy and physiotherapist are synonymous with the North American terms physical therapy and physical therapist.

2. The term 'follow-up instructions' draws on Schegloff's term 'follow-up request' (1992: 1322, footnote 14).

3. Certain characteristics of body movements and their functioning in interaction make them especially significant resources in physiotherapy. Importantly in this context of providing for implied but inexplicit reference to troubles, body movements can form a particularly subtle, tentative, and potentially ambiguous interactional resource (Goffman 1983; Heath 1986: Chapter 2); they have the capacity to be less precise in their meaning than talk (Schegloff 1984). For these reasons, body movement is 'often adopted as a medium of utterance where the utterer seeks to be less fully bound or officially committed to what he or she has to say'; where 'speech might be regarded as too explicit or indelicate' (Kendon 1985: 223).

4. Improvising in this context refers to the important therapeutic activity of adapting generic skills and general principles to the individual and hence responding in a unique way to unique cases (Dingwall et al. 1998).

\section{References}

Beach, W. (1995). Preserving and constraining options: 'Okays' and 'official' priorities in medical interviews. In The Talk of the Clinic: Explorations in the Analysis of Medical and Therapeutic Discourse, G. Morris and R. Chenail (eds.), 259-289. Hillsdale, NJ: Lawrence Erlbaum Associates.

Chafe, W. and Nichols, J. (1986). Evidentiality: The Linguistic Coding of Epistemology. Norwood, NJ: Ablex.

Chartered Society of Physiotherapy (2000). Core Standards, 3rd ed. London: Chartered Society of Physiotherapy.

- (2002). Curriculum Framework for Qualifying Programmes in Physiotherapy. London: Chartered Society of Physiotherapy.

- (2005). Core Standards, Revised ed. London: Chartered Society of Physiotherapy.

Department of Health UK (1999). Patient and Public Involvement in the New NHS. London: Department of Health.

Dickson, D. and Maxwell, M. (1985). The interpersonal dimension of physiotherapy: Implications for training. Physiotherapy 71 (7): 306-310.

Dingwall, R., Murphy, E., Greatbatch, D., Watson, P., and Parker, S. (1998). Catching goldfish: Quality in qualitative research. Journal of Health Services Research and Policy 3 (3): 167-172.

Goffman, E. (1969). The insanity of place. Psychiatry 32 (4): 357-388.

— (1981). Response cries. In Forms of Talk, 78-123. Oxford: Basil Blackwell.

- (1983). The interaction order. American Sociological Review 48: 1-17. 
Heath, C. (1986). Body Movement and Speech in Medical Interaction, Chapter 2. Cambridge: Cambridge University Press.

Heritage, J. (1984). Garfinkel and Ethnomethodology. Cambridge: Polity Press.

Heritage, J. and Stivers, T. (1999). Online commentary in acute medical visits: a method of shaping patient expectations. Social Science and Medicine 49: 1501-1517.

Jefferson, G. (1987). On exposed and embedded correction in conversation In Talk and Social Organisation, G. Button and J. Lee (eds.), 86-100. Clevedon, OH: Multilingual Matters.

Jordan, B. and Henderson, A. (1995). Interaction analysis: foundations and practice. The Journal of the Learning Sciences 4 (1): 39-103.

Kendon, A. (1985). Some uses of gesture. In Perspectives on Silence, D. Tannen and M. Saville-Troike (eds.), 215-234. Norwood, NJ: Ablex.

Lindsay, J. and Wilkinson, R. (1999). Repair sequences in aphasic talk: a comparison of aphasic-speech and language therapist and aphasic-spouse conversations. Aphasiology 13 (4/5): 305-325.

Lynch, M. and Grisogono, V. (1991). Strokes and Head Injuries, 115-116. London: John Murray.

Maynard, D. (1989). Perspective-display sequences in conversation. Western Journal of Speech Communication 53 (Spring): 91-113.

- (1991a). The perspective-display series and the delivery and receipt of diagnostic news. In Talk and Social Structure, D. Boden and D. Zimmerman (eds.), 164-194. Cambridge: Polity Press.

- (1991b). Bearing bad news in clinical settings. In Progress in Communication Sciences, B. Dervin (ed.), 143-172. Norwood, NJ: Ablex.

- (1992). On clinicians co-implicating recipients' perspective in the delivery of diagnostic news. In Talk at Work, P. Drew and J. Heritage (eds.), 331-358. Cambridge: Cambridge University Press.

McHoul, A. (1985). Two aspects of classroom interaction: Turn-taking and correction. Australian Journal of Communication Disorders 13: 53-64.

Mead, J. (2000). Patient partnership. Physiotherapy 86 (6): 282-284.

Mehan, H. (1985). The structure of classroom discourse. In Handbook of Discourse Analysis. Volume 3: Discourse and Dialogue, T. van Dijk (ed.), 119-131. London: Academic Press.

Moffett, J. K. and Richardson, P. (1997). The influence of the physiotherapist-patient relationship on pain and disability. Physiotherapy Theory and Practice 13 (2): 89-96.

Murphy, E. and Dingwall, R. (2003). Qualitative Methods and Health Policy Research, Chapter 5. New York: Aldine de Gruyter.

Parry, R. (2004). The interactional management of patients' physical incompetence: a conversation analytic study of physiotherapy interactions. Sociology of Health and Illness 26 (7): 976-1007.

Parsons, T. (1951). The Social System, Chapters 7 and 10. London: Routledge and Kegan Paul.
Partridge, C. (1994). Evaluation of physiotherapy for people with stroke: Report of a workshop on appropriate outcomes of physiotherapy for people with stroke. London: King's Fund Centre.

Peräkylä, A. (1997). Reliability and validity in research based on tapes and transcripts. In Qualitative Research: Theory, Methods and Practices, D. Silverman (ed.), 201-219. London: Sage.

Peräkylä, A. and Vehviläinen, S. (2003). Conversation analysis and professional stocks of interactional knowledge. Discourse and Society 14 (6): 727-750.

Potter, J. (1996). Representing Reality: Discourse, Rhetoric, and Social Construction. London: Sage.

Robinson, P. (2001). CSP urged to clarify stance on standards: response (letter), Physiotherapy Frontline 7 (November 21st): 27.

Ruusuvuori, J. (this issue). Delivery and reception of the reason for the visit in general practice and homeopathic consultations.

Schegloff, E. (1979). The relevance of repair to syntax-forconversation. Syntax and Semantics 12: 261-286.

- (1984). On some gestures' relation to talk. In Structures of Social Action: Studies in Conversational Analysis, J. Atkinson and J. Heritage (eds.), 266-296. Cambridge: Cambridge University Press.

- (1992). On talk and its institutional occasions. In Talk at Work: Interactions in Institutional Settings, P. Drew and J. Heritage (eds.), 101-134. Cambridge: Cambridge University Press.

- (1993). Reflections on quantification in the study of conversation. Research on Language and Social Interaction 26 (1): 99-128.

Silverman, D. (1997). Discourses of Counselling: HIV Counselling as Social Interaction. London: Sage.

Stachura, K. (1994). Professional dilemmas facing physiotherapists. Physiotherapy 80 (6): 357-360.

Stimpson, G. and Webb, B. (1975). Going to See the Doctor. London: Routledge.

Strong, P. (2001), The Ceremonial Order of the Clinic, Dingwall, R. (ed.), Aldershot: Ashgate.

Weijts, W., Houtkoop, H., and Mullen, P. (1993). Talking delicacy: speaking about sexuality during gynaecological consultations. Sociology of Health and Illness 15 (3): 295-314.

Ruth Parry qualified as a physiotherapist in 1986. After several years' clinical practice, she moved into research. Initially, she was involved in randomized trial work. Ruth then moved into sociology, researching physiotherapist-patient communication using conversation analytic methods. Her current post-doctoral work is funded by the UK Department of Health. It examines how therapists and patients communicate about why treatment activities are being proposed or performed, and investigates aspects of patient involvement in physiotherapy interactions. Address for correspondence: Institute of Work Health and Organisations, University of Nottingham, William Lee Buildings 5, Science and Technology Park, University Boulevard, Nottingham NG7 2RQ, UK.

E-mail: ruth.parry@nottingham.ac.uk 